\title{
Analyzing the impacts of increase in food prices on the households in United Arab Emirates
}

\author{
S. Muhammad*, M. S. Gheblawi and S. A. Al-Neyadi \\ Department of Agribusiness and Consumer Sciences, Faculty of Food and Agriculture, \\ United Arab Emirates University, Al Ain, P.O. Box 17555, United Arab Emirates
}

\begin{abstract}
According to recent statistics, the prices have increased about $14 \%$ in the United Arab Emirates (UAE). This increase in prices has affected the UAE diverse population differently. The main objective of this study was to analyze the perception of UAE household and to assess the economic and social impacts of increases in prices. The results showed that about half of the respondents do not have enough income to meet their daily needs. Majority of the respondents were affected severely with the recent increase in prices. The increase was much higher for rent, food, education and healthcare. Ordered Probit regression model was used to determine the factors affecting severity of increase in prices. The regression results showed that the effect of high prices varied among groups based on their age, ethnicity, gender, educational level and income. The paper provides useful information to policy makers in order to understand the impacts and design programs to deal with increase in prices.
\end{abstract}

Keywords: Food prices, inflation, economic impact, Ordered Probit model, UAE

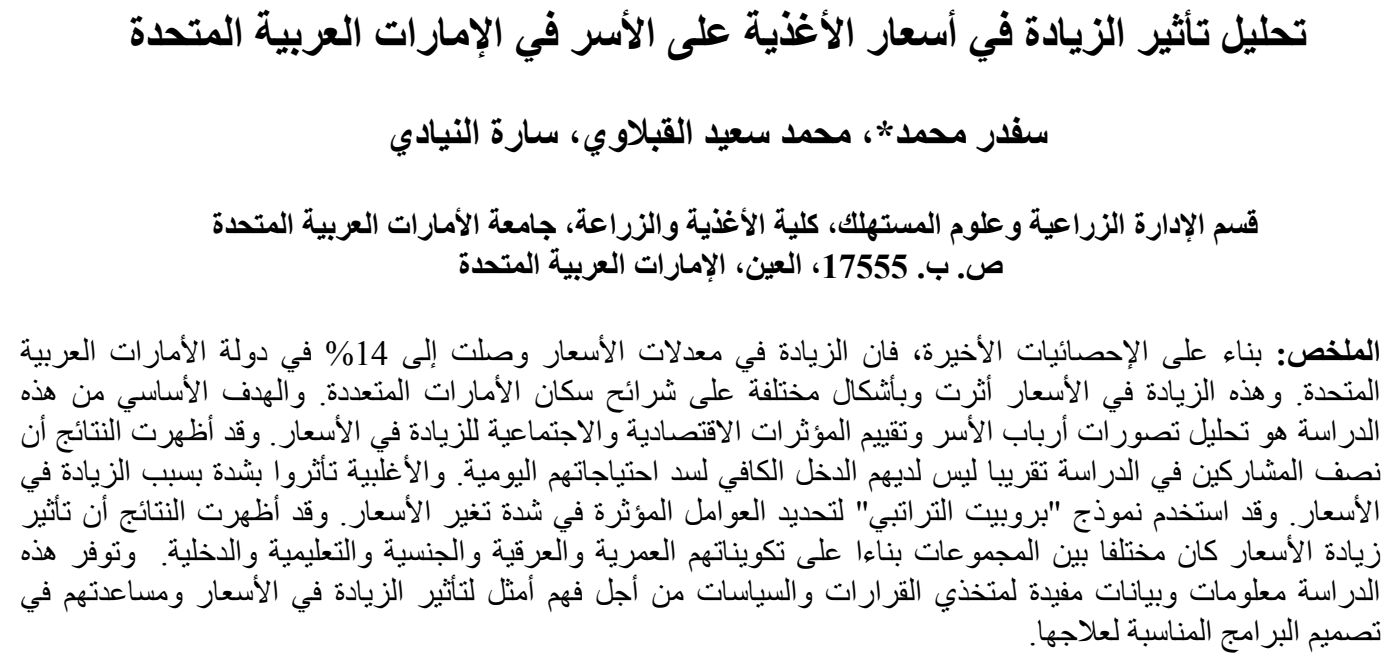

\footnotetext{
*Corresponding author, Email: smuhammad@uaeu.ac.ae
} 


\section{S. Muhammad et al.}

\section{Introduction}

In 2008, the real international food prices reached their highest level since the end of 1970's and for the first time since 1981 the FAO real food price index surpassed the 150 mark, the result of a sharp increase in 2006-07, and was followed by an even steeper increment in 2008. These sharp increases led to social and political instability in a number of developing countries, and prices are expected to continue above the pre-2004 trend level for the foreseeable future (OECD-FAO, 2008).

The reasons for these price increases are complex and include both supply-side and demand-side factors. The long-term structural trends underlying growth in demand for food have coincided with short term cyclical or temporary factors affecting food supply, resulting in a situation in which growth in demand continues to outstrip growth in supply. The supply side factors include lower levels of cereal stocks by world's major cereals producers, which contribute to higher price volatility; production shortfalls due to bad weather; and soaring petroleum prices, which are highly correlated with food prices via fertilizer and transport costs. Demand-side factors include increased demand from the emerging biofuels market and changes in consumption patterns in large emerging economies such as India and China (Zezza, 2009).

The impact of rising food prices on the prevalence of hunger is even more striking. FAO's estimates through the end 2007 show that the proportion of hungry people in the developing world sliding back towards 17 percent, about the same level as a decade ago. The internationally agreed hunger-reduction goals are becoming an enormous challenge when few years remaining to 2015 (FAO 2008).

The Consumer Price Index (CPI) for the United Arab Emirates (UAE) has been increasing gradually in the past few years as shown in Figure 1. The general inflation rate accelerated in the period 2004-2007 as seen in the CPI. The inflation rate of the foodstuffs also increased during the same time period but not as sharply as the general inflation rate.

Figure 1. Inflation rate (\%) in UAE during 1998-2007.

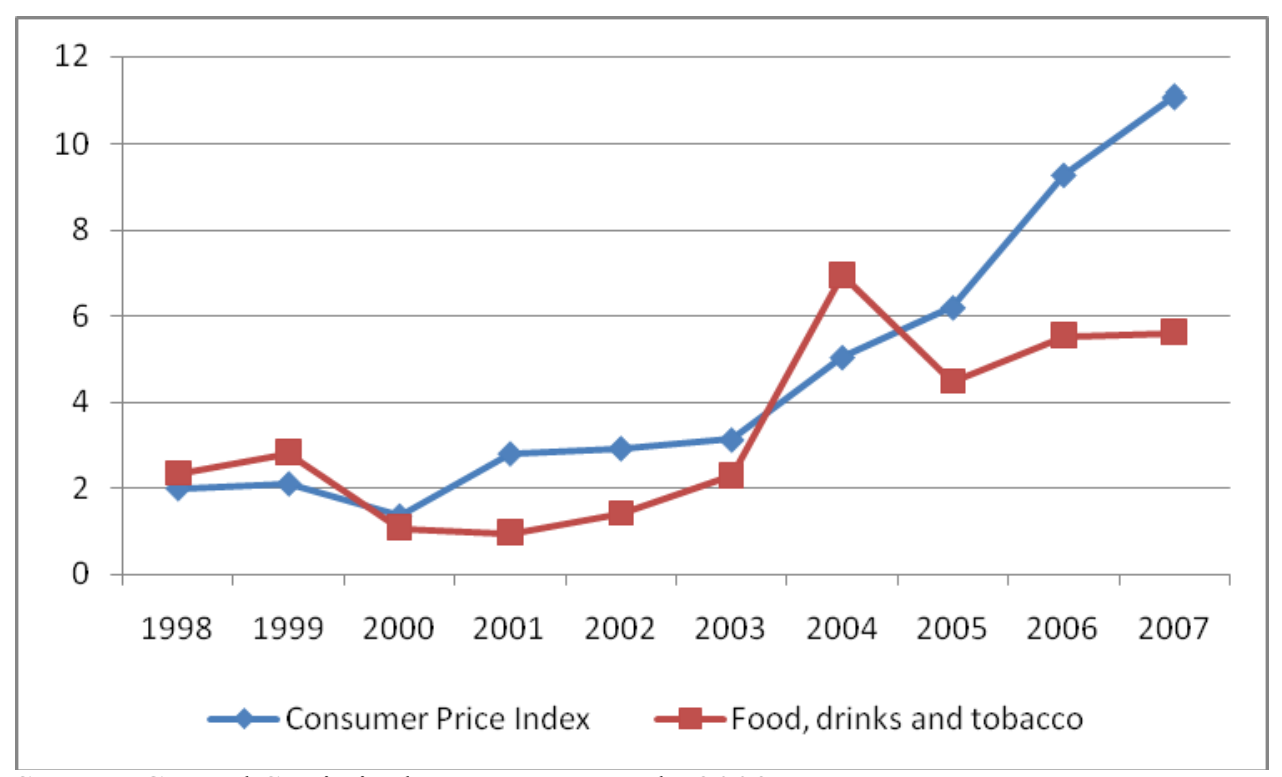

Source: Central Statistical Department, July 2009. 
According to the Central Statistical Department (2009), the CPI during the first half of 2009 reached 114.24 compared to 110.49 for the same period in 2008 . Therefore, the inflation rate for the first half of 2009 was 3.4 percent. The rise in the price of foodstuffs and non-alcoholic beverages contributed 2.7 percent to the increase in the inflation in CPI during that time period. However, CPI witnessed no change from May to June 2009 while the CPI for June 2009 is less than its counterpart of 2008 by 0.03 percent and was mainly due to the decrease in expenditures on housing by 2 percent and on clothes, entertainment and health care by 9.7 percent. The comparison between the average prices of the different food groups for the June months of 2009 and 2008 reveals a decline in prices of some food groups and increases in others as shown in Table 1. It is evident that the prices of some of the major food groups declined after the sharper increases in the prices of foodstuffs observed in prior years. It is this phenomenon of sharp price fluctuations of food that is a concern to planners for food security especially in food importing countries.

Table 1. Rate of change in average prices: June 2009 and June 2008.

\begin{tabular}{ll}
\hline Food Group & $\begin{array}{l}\text { Percent change in average } \\
\text { prices }\end{array}$ \\
\hline Cereals and cereal products & -2.9 \\
Meat and poultry & -3.9 \\
Fruits & -1.6 \\
Dairy products and eggs & -4.0 \\
Vegetables & -7.1 \\
Nuts & -1.5 \\
Spices and food enhancers & -3.3 \\
Fish and seafood products & 0.07 \\
Oils and fats & 4.0 \\
Dry and canned legumes & 9.0 \\
Sugar and sugar products & 1.7 \\
Tea, coffee and cocoa & 5.1 \\
Beverages and confectionaries & 8.3 \\
Alcoholic beverages & 7.7 \\
Tobacco and tobacco products & 13.4 \\
\hline
\end{tabular}

Source: Central Statistical Department, July 2009.

According to the Census in 2005, the UAE population consists of several diverse ethnic groups representing Nationals $(19 \%)$, other Arab and Iranian (23\%), South Asian (50\%), and other expatriates include Westerners and East Asians (8\%). The majority from the sub-continent, millions of South Asians currently reside in the country as migrant workers, principally from India, Pakistan, Bangladesh, Nepal and Sri Lanka. The expatriate workers and particularly low- skilled employees from Asia are traditionally low-paid expatriate workers in the UAE (Keane and McGeehan, 2008). This paper will attempt to analyze the factors affecting the increase in prices on the diverse population groups in the UAE.

\section{Data and Methodology}

The data for this study was collected in the United Arab Emirates. A total of 300 questionnaires were randomly distributed in the seven emirates and 196 respondents 
completed the survey with the response rate of about $65 \%$. The respondents were selected randomly from the different ethnic groups and it was ensured that sample should represent all ethnic groups in the target population. A vast majority of the immigrant population is illiterate but their opinions were important for this study. So, face to face interviews were conducted when necessary along with the translators. The survey questionnaire was tested before the distribution and necessary adjustments were made. The survey questionnaire include information on demographics, respondents' opinion on price increase, severity of impact of prices increase, strategies to deal with increase in prices, and questions capturing the social and economic impacts. Several statistical methods were used to analyze the data using SPSS. The Ordered Probit Regression model was used to determine the factors affecting the severity of high prices on the households in United Arab Emirates.

\section{Empirical Model}

While much recent analysis has focused on the determinants of the trends in international prices, their relative importance, the transmission of prices to domestic markets, and the prospects for future price trends, a number of contributions have emerged that look at the microeconomic impact of the crisis (Ivanic and Martin, 2008; Aksoy and IsikDikmelik, 2008; Dessus et al., 2008; Rios et al., 2008).
Much of the recent work on the household level impact of the high food prices has in fact focused either on their effect on the poverty headcount and poverty gap (Ivanic and Martin, 2008), or the poverty deficit (Dessus et al. (2008), in an analysis limited to urban households. Rios et al. (2008) analyze the possible welfare impact on poor farmers using household survey data from three countries, while Aksoy and Isik-Dikmelik (2008) make a "first pass" at characterizing the welfare impacts of food prices on net food buyers and sellers.

The following Ordered Probit Regression model was used to determine the factors affecting the severity of high prices on the households in United Arab Emirates. The reported severity of high prices was the dependents variable. Explanatory variables include sets of socio-economic and other demographic variables. The choice of the regression model was based on the characteristics of the dependent variable. The severity of high prices was measured using a scale of 1 to 4 , where $1=$ none, $2=$ some, $3=$ medium, and $4=$ severe. The empirical model was defined as

$$
\mathrm{Y}^{*}{ }_{\mathrm{t}}=\beta^{\prime} \mathrm{X}_{\mathrm{t}}+\varepsilon_{\mathrm{t}}
$$

Where $\mathrm{Y}^{*}{ }_{t}$ is unobserved, $\mathrm{X}_{\mathrm{t}}$ is vector of explanatory variables, and $\beta$ is the vector of unknown parameters; and $\varepsilon_{t}$ is the independently and identically normally distributed error term. The description of dependent and explanatory variables is shown in Table 2. 
Emir. J. Food Agric. 2010. 22 (5): 367-376

http://ffa.uaeu.ac.ae/ejfa.shtml

Table 2. Description of Variables for Ordered Probit Regression Model.

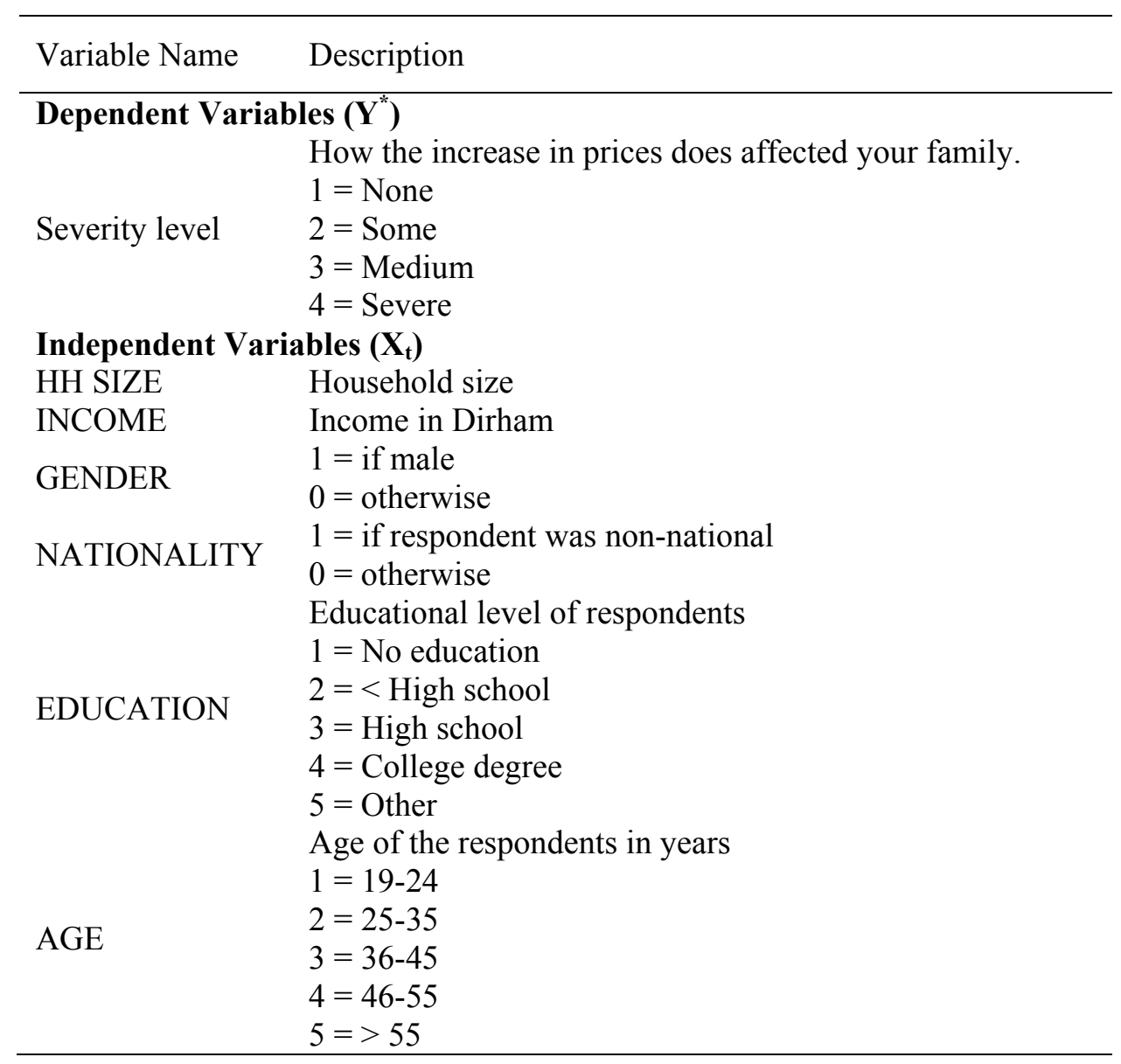

\section{Results and Discussion}

The UAE population consists of several ethnic groups and it is important to compare the socio-economic and other demographic characteristics of these groups. The comparison of demographic characteristics is given in Table 1. The results showed that age distribution of sampled survey among nationals and nonnationals was found significantly different. Similarly, the education and income were also found significantly different among nationals and non-nationals. The majority of the non-nationals $(42.5 \%)$ had less than high school education compared with only $19.2 \%$ for the nationals. Results also showed that about more than half $(51.9 \%)$ of national population surveyed had college degree compared to only $31.2 \%$ for non-nationals. The sampled survey by nationality represents the similar distribution of different ethnic population groups of UAE total population (Census, 2005). It was found that $45.1 \%$ of nonnational had income of less than 2,500 dirham compared with only $5.9 \%$ nationals, less than 5,000 dirham for 74\% non-nationals compared with only $7.9 \%$ nationals, respectively. The results also showed that only $9.1 \%$ of non-nationals have income of 10,000 dirham or more compared with $76.5 \%$ nationals. It was observed that this huge difference in income distribution among national and non-nationals contributed significantly and impact of increase in food prices was much higher on non-nationals than the nationals. 
Table 3. Comparison of the demographic characteristics of the respondents by nationality.

\begin{tabular}{|c|c|c|c|}
\hline & Non-national (\%) & National (\%) & Total (\%) \\
\hline \multicolumn{4}{|l|}{$\mathrm{Age}^{* * *}$} \\
\hline $19-24$ years & 5.6 & 30.8 & 12.4 \\
\hline $25-35$ years & 44.4 & 38.5 & 42.8 \\
\hline $36-45$ years & 35.2 & 25.0 & 32.5 \\
\hline $46-55$ years & 13.4 & 5.8 & 11.3 \\
\hline$>55$ years & 1.4 & 0 & 1.0 \\
\hline \multicolumn{4}{|l|}{ Gender ${ }^{* * *}$} \\
\hline Female & 46.5 & 71.2 & 53.1 \\
\hline Male & 53.5 & 28.8 & 46.9 \\
\hline \multicolumn{4}{|l|}{ Nationality } \\
\hline National & - & 100 & 26.8 \\
\hline Arab Origin & 26.1 & - & 19.1 \\
\hline Asian & 62.7 & - & 45.9 \\
\hline Western/English & 4.2 & - & 3.1 \\
\hline Other & 7.0 & - & 5.2 \\
\hline \multicolumn{4}{|l|}{ Education $^{* * *}$} \\
\hline No education & 17.0 & 1.9 & 13.0 \\
\hline$<$ high school & 25.5 & 17.3 & 23.3 \\
\hline High school & 22.7 & 28.8 & 24.4 \\
\hline College degree & 31.2 & 51.9 & 36.8 \\
\hline Other & 3.5 & 0 & 2.6 \\
\hline \multicolumn{4}{|l|}{ Income $^{* * *}$ (Dirham) } \\
\hline Less than 500 & 3.5 & 0 & 2.6 \\
\hline 500 to 999 & 8.5 & 0 & 6.2 \\
\hline 1,000 to 1,499 & 6.3 & 3.9 & 5.7 \\
\hline 1,500 to 1,999 & 12.7 & 0 & 9.3 \\
\hline 2,000 to 2,499 & 14.1 & 2.0 & 10.9 \\
\hline 2,500 to 4,999 & 28.9 & 2.0 & 21.8 \\
\hline 5,000 to 9,999 & 16.9 & 15.7 & 16.6 \\
\hline 10,000 to 14,999 & 2.8 & 25.5 & 8.8 \\
\hline 15,000 to 24,999 & 2.1 & 21.6 & 7.3 \\
\hline 25,000 or more & 4.2 & 29.4 & 10.9 \\
\hline
\end{tabular}

Several statements were used to determine the effect of increase in price on the UAE households (Table 3) based on different nationalities. The respondents were asked if they have sufficient income to meet their daily needs but about half of the indicated that they do not have sufficient income to meet their daily needs. When compared with the nationalities, it was much higher for non-national $(62 \%)$ when compared with the national population $(9.6 \%)$. The difference on the statement among the population groups was also found statistically significant. A majority of the population (both national and non-national) noticed the increase in price but effect on non-national population was much higher (95.1\%) than nonnational population group $(88.5 \%)$. The respondents were also asked to indicate the severity of increase in prices and how it has affected their households. The respondents were given the choices of none, some, medium and severe. The results showed that the majority of the respondents (42.2\%) experienced medium effect of high prices, while $36.9 \%$ had severe effect. There were only $20.9 \%$ 
respondents with none $(4.2 \%)$ to some $(16.7 \%)$ effect of high prices. The results also indicated that the effect of high prices was different by nationality of the respondents. Majority of non-nationals $(43.5 \%)$ had severe effect of high prices compared to nationals $(18.2 \%)$. Majority of the nationals $(54.5 \%)$ had medium effect compared to non-nationals $(37.9 \%)$. The distribution of the effect of high prices on the respondents by nationality is shown in Figure 2. The effect of high prices on respondents by nationality was also found statistically significant using the ChiSquare statistics.

Table 4. Effect of recent increase in prices on the UAE households (\%).

\begin{tabular}{llll}
\hline & National & Non-national & Total \\
\hline $\begin{array}{l}\text { Do you have enough income to meet } \\
\text { your daily needs? }\end{array}$ & & & \\
Yes & 90.4 & 38.0 & 52.1 \\
No & 9.6 & 62.0 & 47.9 \\
Have you notices the recent price & & & \\
increase? & 98.1 & 98.6 & 98.4 \\
Yes & 1.9 & 1.4 & 1.6 \\
No & & & \\
Did increase in price affect you and & & & \\
the family? & & 95.1 & 93.3 \\
Yes & 88.5 & 4.9 & 6.7 \\
No & 11.5 &
\end{tabular}

***Significant at the 0.01alpha level

* Significant at the 0.10 alpha level

Figure 2. Severity Level of increase in prices on UAE household.

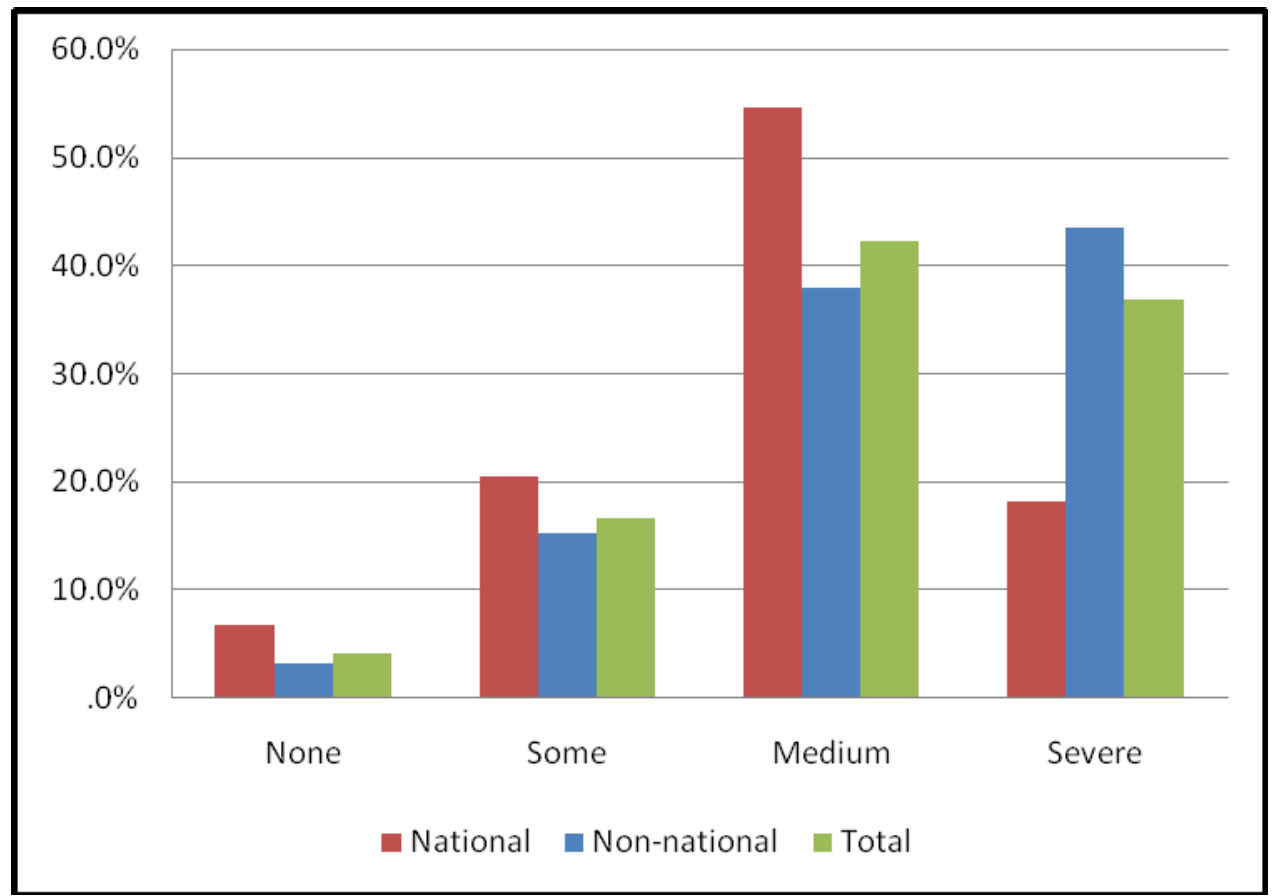

$\chi^{2}$ (Chi-Square) value $=9.310$ and significant at the 0.05 level. 
The respondents were asked to indicate the effect of high prices on several categories. There was significant increase in overall cost of living for all respondents. The mean response on severity of high prices is shown in Table 4, where $1=$ no effect and $4=$ severe effect. The most effect was observed for food (mean value of 3.63), followed by rent (3.46) and education
(3.41). The effect of high prices was from medium to severe for all categories. The effect of high prices was also analyzed by the nationality of the respondents. The data showed that the effect was much higher on non-nationals compared to the nationals in all categories. The effect on rent and education was found higher for nonnationals and found statistically significant.

Table 5. Mean Increase of cost of different categories in the last year.

\begin{tabular}{llll}
\hline & National & Non-national & Total \\
\hline Rent $^{*}$ & 3.27 & 3.52 & 3.46 \\
Utilities (Electricity, water, telephone, etc.) & 3.06 & 3.32 & 3.24 \\
Food & 3.65 & 3.63 & 3.63 \\
Education $^{* * *}$ & 3.09 & 3.54 & 3.41 \\
Healthcare & 3.30 & 3.37 & 3.35 \\
Overall cost of living & 3.70 & 3.74 & 3.73 \\
\hline
\end{tabular}

(Where $1=$ None, $2=$ Some, $3=$ Medium, and $4=$ Severe)

***Significant at the 0.01alpha level

* Significant at the 0.10 alpha level

\section{Regression Results}

The results of the Ordered Probit model for factors affecting the severity of high prices on the UAE households are shown in Table 5. The results indicate that household size, income, nationality, education and age were the main determinants in the estimated model. The results show those larger size households were more likely in the higher severity level due to increase in the prices. On the other hand, households with higher income are more likely in the lower severity level than those with low incomes. The UAE is characterized with large expatriate population about $82 \%$ (Census, 2005). The increase in prices affected this group of population much more than the nationals. The model results show that non-national households are more likely in the higher severity level than the nationals. The respondents with less than high school education are more likely in the higher severity level when compared with the other education category. The age of the respondents was also a significant factor affecting the severity level. According to the results, the younger individuals are more likely in the higher severity level compared to the individuals with the age of 55 or more. The results from the model will help policy makers to understand the impacts of increases in prices on the households based on socio-economic characteristics and formulate strategies to tackle this problem accordingly.

Appropriate tests were performed to check the existence of multicollinearity and dismissed not only by looking at the correlation matrix of explanatory variables, but also by regressing each explanatory variable on the remaining explanatory variables as suggested by Johnston (1984) and examining the $\mathrm{R}^{2} \mathrm{~s}$ of each regression equation. 
Table 6. Ordered Probit Regression Results to Analyze Factors affecting the UAE Households.

\begin{tabular}{|c|c|c|c|c|}
\hline & Estimate & Std. Error & Wald & Sig. \\
\hline $1=$ None & .576 & 1.063 & .293 & .588 \\
\hline $2=$ Some & 1.602 & 1.066 & 2.257 & .133 \\
\hline $3=$ Medium & 2.996 & 1.077 & 7.738 & .005 \\
\hline HH SIZE & $.055^{* * *}$ & .020 & 7.862 & .005 \\
\hline Income & $-.112^{* *}$ & .047 & 5.687 & .017 \\
\hline Gender & .073 & .187 & .153 & .696 \\
\hline Nationality & $.485^{*}$ & .276 & 3.093 & .079 \\
\hline \multicolumn{5}{|l|}{ Education } \\
\hline $1=$ No education & .176 & .541 & .105 & .746 \\
\hline $2=<$ High school & $1.033^{* *}$ & .526 & 3.860 & .049 \\
\hline $3=$ High school & .679 & .523 & 1.687 & .194 \\
\hline $4=$ College degree & .858 & .526 & 2.661 & .103 \\
\hline \multicolumn{5}{|l|}{ Age } \\
\hline $1=19-24$ & 1.114 & .841 & 1.755 & .185 \\
\hline $2=25-35$ & $1.813^{* *}$ & .809 & 5.023 & .025 \\
\hline $3=36-45$ & $2.147^{* * *}$ & .811 & 7.008 & .008 \\
\hline $4=46-55$ & $1.594^{*}$ & .828 & 3.704 & .054 \\
\hline
\end{tabular}

\section{Summary and Conclusions}

The inflation rate in the United Arab Emirates has increased significantly in the recent years. This increase in prices has severely affected the diverse population residing in the UAE. The results have indicated that severity of prices increase was higher based on ethnicity and income level. There was significant increase in the costs of rent, utilities, food, education, healthcare and overall cost of livening for both UAE nationals and non-nationals. But the results also showed that the effect was higher for non-nationals compared with the nationals. The majority of the nonnational population living in UAE is unskilled, uneducated and working in the low paying labor sector. The regression analysis (Ordered Probit) was used to analyze the effect of high prices on the severity level of households in UAE. The regression results showed that th effect of high prices vary among groups based on their age, ethnicity, gender, educational level and income. The results from this study will help policy makers to understand and assess the economic and social impact of high prices on the households and formulate strategies and programs to deal with the issue. The government support to provide subsidy and other measures to control high prices will be great relief to the low income families.

\section{References}

Aksoy, A. and A. Isik-Dikmelik. 2008. Are Low Food Prices Pro-Poor? Net Food Buyers and Sellers in Low-Income Countries. World Bank Policy Research Working Paper No. 4642. 
Dessus, S., S. Herrera, and R. de Hoyos. 2008. The impact of food inflation on urban poverty and its monetary cost: some back-of-the-envelope calculations. Agric. Econ 39:1. November.

FAO. 2008. Hunger on the rise: Soaring prices add 75 million people to global hunger rolls Briefing paper: September 08.

Ivanic, M. and W. Martin. 2008. Implications of higher global food prices for poverty in low-income countries. Agric. Economics. 39:1, November.

Johnston J. 1984. Econometric Methods, McGraw Hill, Inc., New York.

Keane, D., and N. McGeehan. 2008. Enforcing Migrant Workers' Rights in the United Arab Emirates. International J. Minority Group Rights 15:81-115.
OECD-FAO. 2008. OECD-FAO Agricultural Outlook 2008-2017. Paris and Rome.

Central Statistical Department. 2009. Ministry of Economy, Inflation rates and Consumer prices.

Census. 2005. Ministry of Economy and Planning, Al Manara Jewelry Building, Hamdan Street, Abu Dhabi, UAE.

(http://tedad.ae/english/population_res ults.html [Accessed May 3, 2010]

Rios, A. R., W.A. Masters and G.E. Shively. 2008. Agricultural Prices and Income Distribution among Farmers: A whole-Household, Multi-Country, Multi-Year Analysis. Purdue University, Mimeo, May 25.

Zezza, A., B. Davis, C. Azzarri, K. Covarrubias, L. Tasciotti., and G. Anriquez. The Impact of Rising Food Prices on the Poor. International Association of Agricultural Economists Conference, Beijing, China, August 16-22, 2009. 